\title{
El Ayuntamiento de Salamanca (1812-1814)
}

\author{
Jesús Rubio Carrero \\ José Ángel Sánchez Galán
}

\begin{abstract}
Sumario: I. INTRODUCCIÓN.-II.MARCO TEMPORAL.-III.EL RÉGIMEN MUNICIPAL DURANTE LA OCUPACIÓN FRANCESA. - IV. LA APLICACIÓN DE LA CONSTITUCIÓN DE 1812 EN EL AYUNTAMIENTO SALMANTINO. 1. Elecciones. 2. Cargos. 3. Competencias. 3.1. Salubridad. 3.2. Orden público. 3.3. Repartimiento y contribución. 3.4. Educación. 3.5. Hospitales. 3.6. Obras públicas. 3.7. Beneficencia. 4. Cumplimiento de las órdenes superiores. 5. Desacuerdos y votaciones. 6. Oligarquías municipales. - V. CONCLUSIÓN. - VI. FUENTES. - VII. BIBLIOGRAFÍA.
\end{abstract}

\section{INTRODUCCIÓN}

Vamos a intentar analizar el período de la primera implantación liberal en el Ayuntamiento de Salamanca en el contexto de la Constitución de 1812. Nuestra labor consistirá en descubrir si existe un verdadero cambio con respecto al Ayuntamiento del Antiguo Régimen. Para ello, utilizaremos las Actas Municipales del Ayuntamiento de Salamanca de los años 1812, 1813 y 1814 así como la bibliografía existente sobre el tema del municipio liberal en esta época, el propio texto constitucional de Cádiz, etc. Mediante el estudio de los cargos municipales, de sus funciones, de las atribuciones y problemas del Ayuntamiento, de las oligarquías urbanas, etc. procuraremos demostrar que no se produce un cambio radical sino más bien una continuidad con respecto a la etapa anterior.

\section{MARCO TEMPORAL}

Tras la aprobación de la Constitución el 19 de marzo de 1812, el 23 de mayo se da la orden de formación de ayuntamientos constitucionales ${ }^{1}$, pero en esa fecha Salamanca aún estaba ocupada por los franceses. El 17 de junio de 1812 se produce la entrada del duque de Wellington en Salamanca ${ }^{2}$. Los últimos reductos franceses aguantan dentro de la ciudad hasta el 23 del mismo mes y al día siguiente se celebra el primer consistorio que recogen las actas bajo el encabezamiento Valga para el Reynado de S.M.C. el Sr. Fernando $V I I, \ldots{ }^{3}$

\footnotetext{
1 ARtola (1978): 480.

2 Villar y Macías (1975).

3 Acta del 24 de junio de 1812.
} 
Desde que los últimos franceses son expulsados, transcurre una fase que denominaremos de «transición», que irá desde el 24 de junio al 16 de agosto de 1812 y dará paso a la composición del primer ayuntamiento constitucional.

En esa sesión de 24 de junio de 1812, podemos observar en la formación del ayuntamiento cómo los componentes del consistorio francés se repiten ahora en el español, junto con algunos nuevos miembros; sólo se echa en falta del ayuntamiento francés la figura del corregidor así como la del secretario. Don Carlos de España da tres órdenes:

- Se nombra Alcalde Mayoral Doctor a D. Francisco CANTERo (del gremio y claustro de la Universidad).

- Quienes formaban el ayuntamiento anterior (francés) deben continuar en sus cargos.

- D. Esteban MejíA desempeña la intendencia de la ciudad y provincia interinamente.

La ausencia de cambios se reafirma con la decisión de reponer en sus respectivos puestos a los antiguos empleados que habían sido depuestos por el anterior gobierno francés ${ }^{4}$ y con la aparición de José María PUENTE con el «Real título de Corregidor por Su Magestad», según el Real Decreto de 17 de noviembre de 1809. El Rey le adjudica las funciones propias de corregidor: «tenga el oficio de mi corregidor de esa ciudad y sus tierras con los de Justicia, Jurisdicción cibil y criminal, y alguacilazgo, por espacio de seis años...» ${ }^{5}$.

Observamos por tanto que continúan los cargos anteriores a la Constitución liberal de Cádiz y es que el Ayuntamiento aún no había recibido el texto de la Constitución y así difícilmente podía aplicarse la misma.

Por fin, el 12 de julio, el Ayuntamiento recibe el texto de la Constitución sancionado por las Cortes Generales y Extraordinarias. Rápidamente se forma una comisión «para la Ejecución de tan soberanas leyes Constitucionales» y preparar las funciones para la celebración subsiguiente ${ }^{6}$.Esta comisión desempeña su trabajo durante un mes y cuatro días. Así, el período de «transición» lo podemos dar por concluido el 16 de agosto de 1812, día en que se celebran las elecciones para formar el Ayuntamiento constitucional.

\footnotetext{
4 Acta del 30 de junio de 1812.

5 Acta del 10 de julio de 1812. Se trata de un nombramiento absolutamente característico del Antiguo Régimen. En el acta encontramos la sentencia «el Rey se guarda el poder de relevarlo», prerrogativa propia del sistema absolutista.

6 Pensamos que la fiesta sería similar a la descrita por José Luis ComELLAS en el artículo citado en la bibliografía: «los ciudadanos no deben entender la proclamación de la Constitución (se lee en un balcón o Ayuntamiento), pero gritan ¡Viva la Constitución! y se van de fiesta, que concluía con un baile público».
} 
Pasamos entonces a una primera fase dentro del Ayuntamiento constitucional salmantino que se prolonga desde la sesión del 17 de agosto (distribución de cargos, formación de comisiones) a la del 13 de noviembre de 1812, último consistorio antes de la vuelta de los franceses, que ocupan de nuevo la ciudad el 15 de noviembre. Su presencia en el Ayuntamiento salmantino se va a prolongar desde el 25 de noviembre (primera reunión) hasta el 30 de abril de 1813 (última).

El ejército español «reconquista» definitivamente la ciudad el 24 de mayo de 1813 dando paso al regreso del Ayuntamiento constitucional, cuya primera reunión se celebra el 27 de mayo, comenzando así una segunda fase de actuación que se extiende hasta el 12 de agosto de 1814, pues el 18 de agosto ya tenemos formado el Ayuntamiento absolutista con las mismas personas que desempeñaban esos cargos en 1808, según Real Cédula del 30 de julio de 1814.

Pero no se puede afirmar que el Ayuntamiento constitucional exista como tal hasta el 12 de agosto. Podríamos decir que a partir del decreto real del 4 de mayo de 1814 se va a poner fin paulatinamente al sistema liberal en Salamanca. Esta orden suprimía el cargo de jefe político; en este sentido, la última aparición del mismo en las actas tiene lugar el 13 de mayo. Por otra parte, el 17 de mayo aparece en las actas el cargo de Alcalde Mayor, absolutamente vinculado con el Antiguo Régimen, aunque no se constata cuándo se produjo su restauración y nombramiento. A continuación, el 22 de junio, toma posesión como Gobernador militar y político de Salamanca y Presidente del Ayuntamiento el señor Comandante don Luis Antonio Rueda, con lo que se daba otro paso para la vuelta del Antiguo Régimen. El 25 de junio se dio una Real Cédula en la que se ordenaba la continuidad de los Ayuntamientos, de los jueces de primera instancia con el nombre de corregidores y alcaldes mayores, el restablecimiento de audiencias y chancillerías y la extinción de Diputaciones Provinciales y Juntas de Censura, orden que fue recibida en Salamanca el 5 de julio y cumplida inmediatamente. Por último, y como ya hemos mencionado anteriormente, la Real Cédula de 30 de julio de 1814 llega a Salamanca el 12 de agosto y también se ejecuta al instante:

«Se vio la Real Cédula de S.M. fecha 30 de julio último por la que se manda que cesen los presentes Ayuntamientos y entren a ejercer los individuos que lo eran en 1808. Cuia real cédula se obedeció con el respeto debido y se acordó se guarde y cumpla en todas sus partes y en su consequencia, a acto continuo, se mandó citar a todos los regidores, diputados y personeros del común de 1808 y que concurriesen a ser posesionados...» ${ }^{7}$.

Una vez situados cronológicamente, podemos tratar otros temas.

$7 \quad$ Acta del 12 de agosto de 1814. 


\section{EL RÉGIMEN MUNICIPAL DURANTE LA OCUPACIÓN FRANCESA}

Los franceses imponen un nuevo ayuntamiento que se debía regular de acuerdo con la idea de reforma municipal de José I. La cuestión era buscar una administración centralizada que hiciera frente a la crisis bélica y preservara la integridad territorial de España.

¿Cómo debía estar organizado el Ayuntamiento según los franceses? Debía tener un corregidor, regidores, un procurador del común, un sustituto de éste y por último un escribano secretario. La figura principal sigue siendo el corregidor, pero ahora los municipios pierden importancia, están supeditados al gobierno central por causa de la guerra, «los municipios quedan totalmente bajo la dependencia de los prefectos» ${ }^{8}$.

En la Salamanca ocupada, existe el cargo de corregidor. Todo lo que acordaba el Ayuntamiento debía ir aprobado y firmado por él. Según puede apreciarse en las actas, el corregidor se sitúa por encima de los regidores. Sus funciones, según estas fuentes, son las de decidir quién ocupa determinados puestos en la ciudad como el de carpintero, abogado, médicos, etc., se encarga de los arrendamientos y obras públicas y, sobre todo, de las cuestiones económicas, aunque no tiene poder sobre la contribución.

En el período francés encontramos 12 regidores para el año de 1812 y 6 regidores para 1813 o al menos son los únicos que aparecen en las actas. Los regidores se reparten las distintas comisiones del Ayuntamiento. Con los franceses existen 6 comisiones permanentes en 1813 que son las de Obrero Mayor, Escuelas de Primeras Letras, Camarillas y Reposo, Alojamientos, Repartimientos y Fiestas.

Según la legislación francesa, en un municipio de más de 5000 habitantes el corregidor debía ser nombrado por el rey. Éste es el caso de Salamanca. En un primer momento se nombra como corregidor interino «por orden del Rey José Napoleón» a Pedro Marcos Rodrigo ${ }^{9}$ ante la ausencia de José Condado, quien ocupará el cargo con la entrada del nuevo año, como lo había hecho también en la anterior etapa de ocupación francesa. En cuanto a los regidores, las actas nos dicen que eran nombrados por el señor prefecto ${ }^{10}$.

Los problemas del Ayuntamiento francés son casi exclusivamente de índole económica a pesar de que el rey manda unas cantidades de dinero reguladas por

\footnotetext{
8 SÁNCHEZ-ARCILla BERNAL (1983): 647.

9 Acta del 25 de noviembre de 1812.

10 Acta del 7 de enero de 1813.
} 
ley pero que se agotan rápidamente ${ }^{11}$ : pagos de deudas y sueldos ${ }^{12}$, problemas de arrendamientos, repartimientos para conseguir dinero para los niños expósitos, alojamiento de militares, falta de dinero en los hospitales, escasez de trigo y cebada, etc. La carestía es tal que los soldados franceses cometen abusos para conseguir pan y trigo ${ }^{13}$.

Las circunstancias de guerra condicionan toda la actividad municipal y la reforma es imposible de llevar a la práctica en su totalidad. Son escasas las atribuciones del Ayuntamiento pero no se ve una subordinación tan exagerada como la propugnada por la legislación francesa. Una muestra de que el Ayuntamiento en el régimen francés tiene menos influencia que bajo el sistema liberal español son las funciones que se le asignan mediante las comisiones antes mencionadas y también el escaso número de reuniones que se celebran pues en los aproximadamente seis meses de la segunda ocupación francesa el Consistorio sólo llega a reunirse en dieciséis ocasiones, en contraste con el elevado número de consistorios constitucionales españoles.

\section{LA APLICACIÓN DE LA CONSTITUCIÓN DE 1812 EN EL AYUNTAMIENTO SALMANTINO}

Vamos a desarrollar distintos aspectos dentro del funcionamiento del Ayuntamiento de Salamanca a raíz de la entrada en vigor de la Constitución de 1812:

\section{Elecciones}

Procedemos a analizar cómo se celebran las elecciones para acceder a un cargo del Ayuntamiento salmantino. ¿Qué dice la Constitución sobre este aspecto? Todos los cargos serían de carácter electivo, con lo que se acababa con la vinculación y perpetuidad de oficios, cualquiera que fuese el título y denominación. Para las elecciones se impuso un mecanismo indirecto. Primero se nombrarían unos vecinos que representarían a todo el pueblo en la votación final. Nadie podía negarse a aceptar el cargo (carga concejil). La Constitución recoge esta cuestión en los artículos 310,311, 312, y cuestiones relacionadas con los posibles elegidos (condiciones) en los artículos 313-317.

En primer término, establece el sistema: «Los alcaldes, regidores y procuradores síndicos se nombrarán por elección en los pueblos, cesando los regidores perpetuos cualquiera que sea su título» ${ }^{14}$. A continuación:

\footnotetext{
11 Acta del 10 de diciembre de 1812.

12 Acta del 1 de febrero de 1813.

13 Acta del 25 de noviembre de 1812.

14 Artículo 310 de la Constitución.
} 
«en el mes de diciembre de cada año se reunirán los ciudadanos de cada pueblo para elegir a pluralidad de votos cierto número de electores proporcionado a su vecindario, que residan en el mismo pueblo y estén en el ejercicio de los derechos de ciudadano» ${ }^{15}$.

Ante la necesidad de crear el nuevo Ayuntamiento no se espera a diciembre para elegirlo realizándose las elecciones en agosto de 1812.

El número de electores correspondiente a Salamanca era de diecisiete. Estos electores «nombrarán en el mismo mes a pluralidad absoluta de votos el alcalde o alcaldes, regidores y procurador o procuradores síndicos, para que entren a ejercer cargos el $1 .^{\circ}$ de enero del siguiente año» ${ }^{16}$. En este caso, dadas las circunstancias, se celebran las elecciones el 16 de agosto de 1812 y el 17 se juran ${ }^{17}$ los cargos. La fórmula de juramento que se sigue y que encontramos repetidamente en las actas es ésta:

«Entrando en pie y puesta la señal de la cruz, juraron por Dios Nuestro Señor y Sus Santos Evangelios de guardar y hacer guardar y cumplir la constitución política de la Monarquía Española sancionada por las Cortes Generales y Extraordinarias de la Nación y ser fieles al Rey. Igualmente que guardaron el voto que la ciudad tiene hecho a la pura y limpia concepción de María Santísima y cumplir en todo con las ordenanzas desta Ciudad» ${ }^{18}$

El Ayuntamiento de Salamanca quedó formado por dos alcaldes, doce regidores y dos procuradores síndicos. Los elegidos en las elecciones de 1812 fueron:

- señores alcaldes: Alcalde Primero, Don Anselmo Prieto Hermosino; Alcalde Segundo, Don Martín YNOJOSA.

- señores regidores: Francisco NIETO DE LA HOZ, Miguel MARTEL, Diego GONZÁLEZ, Andrés MERCHANTE, Manuel DELGADO — arcediano de Ledesma - , Agustín Herrero, Patricio CorTés, Matías Villar, Excelentísimo Señor Marqués de Cerralbo, José MinTEgui, Baltasar PAVón y Juan BAQUERO.

- señores procuradores síndicos: José AYUSO y Juan BELlo.

¿Qué dice la Constitución sobre la continuación de los cargos? «Los alcaldes se mudarán todos los años; los regidores por mitad cada año, y lo mismo los procuradores síndicos donde haya dos; si hubiere sólo uno se mudará todos los años» ${ }^{19}$. Los dos alcaldes, seis regidores y uno de los procuradores síndicos deberían ser reemplazados en nuestro caso. Vamos a comprobarlo.

\footnotetext{
15 Artículo 311 de la Constitución.

16 Artículo 312 de la Constitución.

17 Artículo 334 de la Constitución.

18 Acta del 17 de agosto de 1812.

19 Artículo 313 de la Constitución.
} 
Las siguientes elecciones debían celebrase en diciembre de 1812, pero debido a la nueva ocupación francesa, no se celebran hasta el 30 de mayo de $1813^{20}$, una vez liberada la ciudad. Éstos fueron los elegidos:

- señores alcaldes: Alcalde Primero, Don Antonio RASCón, vizconde de Revilla; Alcalde Segundo, Licenciado Don José DELGADO.

- señores regidores: Diego GonZÁlEZ, Matías VILlaR, Excelentísimo Señor Marqués de Cerralbo, José MinTEGUI, Baltasar PAVÓN, Juan BAQUERO, Marcos MARTín, Agustín GonZÁlez, Joaquín LAONERO, Manuel DELGADO, Juan DomíngueZ y José BÁZQUEZ.

- señores procuradores síndicos: Juan BELlO y Pedro TiBURCIO GuTIÉRREZ.

Observamos que sí se cumple la Constitución ${ }^{21}$. Los dos alcaldes son nuevos, los seis primeros regidores citados en la lista continúan del Ayuntamiento precedente, los seis siguientes son de nueva elección y Juan BELLO permanece como procurador síndico mientras que Pedro TIBURCIO sustituye a José AYUSO en este cargo. Falta saber si esto se cumple en las siguientes y últimas elecciones, celebradas el 26 de diciembre de 1813:

- señores alcaldes: Alcalde Primero, Don Martín José LATARAIN; Alcalde Segundo, Don Joaquín PEYRó.

- señores regidores: Marcos MARTín, Joaquín LAONERO, Manuel DELGADO, José BÁzQUEZ, Juan Domínguez, Agustín GonZÁlEZ, Francisco DE LAS HERAS, José LOBARINAS, Joaquín LóPEZ DE AYALA, Nicolás José DE LIES, Excelentísimo Señor Marqués de la Escala y Juan Manuel VICENTE.

- señores procuradores síndicos: Juan SANTOS MORÁN y Antonio NúÑEZ ESCARPIRO.

Se vuelve a cumplir la normativa constitucional, pero hemos de mencionar algunas peculiaridades que se dan en el transcurso del segundo Ayuntamiento: El 25 de agosto de 1813, Juan SANTOS Morán sustituye a Juan BELlO como procurador síndico debido a que éste es elegido para formar parte de la Diputación Provincial ${ }^{22}$. A Juan SANTOS MORÁN, por tanto, le correspondía marcharse del Ayuntamiento a partir del 1 de enero de 1814, pero no es así, ya que el otro síndico, Pedro TIBURCIO GUTIÉRREZ está enfermo y renuncia a su cargo, siendo reemplazado por Antonio NÚÑEZ ESCARPIRO. El otro caso es el del regidor José

\footnotetext{
20 En reunión extraordinaria del Consistorio de 28 de mayo de 1813 se decide celebrar las elecciones dos días después. Lo vemos en el «Acta de 28 de mayo de 1813 por la tarde».

21 Se cumple siempre y cuando la figura de Manuel DELGADo de estas segundas elecciones no se corresponda con la del anterior consistorio. Entendemos que son personas distintas, ya que al elegido en este caso no le acompaña el cargo de arcediano de Ledesma.

22 Acta del 21 de agosto de 1813.
} 
MiNTEGUI, sustituido el 13 de septiembre de 1813 por Mauricio BARADART, al haber sido designado Diputado de las Cortes ${ }^{23}$. En este caso, y como era preceptivo, Mauricio BARADART no continúa en el Ayuntamiento de 1814, pues sustituía a un miembro que debía marcharse.

Una vez analizadas las elecciones, apoyamos la opinión de Miguel ARTOLA sobre la dificultad de imponer el sistema constitucional por causa del poco tiempo del que dispuso, ya que, al menos en Salamanca, ningún Ayuntamiento completo, de los tres que se eligen según la Constitución, logra desempeñar sus funciones durante un año seguido. Eso sí, todos los procesos se hacen de acuerdo a lo previsto constitucionalmente.

\section{Cargos}

La figura del corregidor tiene en el Antiguo Régimen la autoridad suprema dentro del Ayuntamiento, elegido y nombrado por el rey, a través del Consejo de Castilla primero y de la Cámara de Castilla después. Observamos que este cargo desaparece tras la implantación del nuevo sistema. Lo encontramos en nuestras actas hasta las primeras elecciones constitucionales y también bajo la dominación francesa.

La función más parecida en el nuevo sistema es la que desempeña el alcalde primero. La gran diferencia respecto al corregidor es que no es elegido por el rey sino por el pueblo mediante sufragio censitario e indirecto. Viene a realizar las mismas labores exceptuando la judicial (aunque tiene la misión de conci$\operatorname{liar}^{24}$ ), reservada al juez de primera instancia; para ocupar este cargo se busca «gente apropiada para ser jueces», para lo que se recurre a los antiguos corregidores y alcaldes mayores ${ }^{25}$. El Ayuntamiento de Salamanca propone cinco sujetos para ese puesto y es elegido el licenciado don Peregrino ORTIZ el 5 de julio de $1813^{26}$. Por la lista de candidatos comprobamos que el desempeño de este cargo es compatible con funciones dentro del Ayuntamiento (por ejemplo, el alcalde segundo formaba parte de la lista).

El alcalde segundo lo deberíamos relacionar con los alcaldes mayores del Antiguo Régimen. Éstos eran justicias auxiliares de los corregidores, atribuyéndoseles en muchos casos las mismas facultades, pero siempre supeditados a él. Asumían la función del corregidor cuando éste no asistía al consistorio, al

\footnotetext{
23 Acta del 6 de septiembre de 1813.

24 Artículos 278, 279 y 280 de la Constitución. Parece que este aspecto no estaba muy claro para el Ayuntamiento pues encontramos en el acta del 6 de septiembre de 1813 un oficio de la Regencia del Reino por medio del jefe político en el que se recuerda al Ayuntamiento que «el conocimiento de los juicios de conciliación corresponde a los alcaldes constitucionales».

25 Acta del 2 de julio de 1813.

26 La elección fue un tanto accidentada y discutida. Remitimos a las actas de los días 5 y 9 de julio de 1813.
} 
igual que los alcaldes segundos hacen con los primeros ${ }^{27}$. Se diferencian en que los alcaldes mayores son elegidos por el rey o el corregidor y los alcaldes segundos lo son por el mismo mecanismo que los alcaldes primeros.

La figura del jefe político nace en este periodo. Al igual que el alcalde primero, lo podríamos relacionar con el corregidor del Antiguo Régimen en tanto que es figura de designación real y representante del poder central en la provin$\mathrm{cia}^{28}$. Preside el Ayuntamiento de la capital de su provincia cuando asiste a las reuniones, pero sin voto (sólo tiene el voto decisivo en caso de empate) ${ }^{29}$. Durante el primer gobierno desempeña el cargo el Marqués de Espeja ${ }^{30}$. Tras la segunda ocupación francesa, la Regencia del Reino en comisión de la provincia de Salamanca nombra a José MINTEGUI jefe político pero este nombramiento no tiene efecto ya que dicha potestad le corresponde al rey, que nombra a Francisco DE SALES CANTERO ${ }^{31}$. En ambos casos se observa cómo se pide celeridad en el desempeño de sus funciones: creación de Ayuntamientos constitucionales en toda la provincia, observancia de los decretos constitucionales, cese de los colaboradores del gobierno intruso, fin del uso de moneda francesa...

Los regidores mantienen las mismas facultades que en el Antiguo Régimen, salvo por el carácter de su elección, antes real y ahora mediante proceso electoral.

La figura del procurador síndico personero también está presente. En este caso, al ser Salamanca una ciudad de cierta entidad, tiene dos síndicos. Entre sus funciones están la de supervisar la limpieza de calles, cuestiones sobre la cárcel, las obras públicas y dar informes respecto a las purificaciones de cargos. Los síndicos buscaban información en el pueblo sobre la conducta de determinadas personas que ocupaban cargos de la administración de rentas durante la dominación francesa. Según fuera el informe positivo o negativo, se mantenía o no en su puesto a esa persona. La lista de investigados es muy amplia ${ }^{32}$.

Los alcaldes de barrio son elegidos por las distintas parroquias. La ciudad se dividía en cuarteles y parroquias donde cada alcalde de barrio ejercía su ju-

\footnotetext{
27 Acta del 22 de abril de 1814 .
}

28 Artículo 322 de la Constitución: «el gobierno político de las provincias reside en el Jefe Superior nombrado por el Rey en cada una de ellas»

29 Con fecha del 19 de julio de 1813 se trata el caso de Bernardo Zurbano; el Ayuntamiento vota para decidir si lo mantiene en su puesto en la administración de rentas o es destituido por colaboración con el gobierno intruso. La votación se salda con empate. Es entonces cuando se recurre al voto del jefe político, decidiendo éste que Zurbano mantenga su puesto. Acta del 19 de julio de 1813.

30 Acta del 19 de octubre de 1812. El Marqués jura el cargo, pero la peculiaridad es que el nombramiento lo realiza el ejército y no el Rey (Acta del 16 de octubre de 1812)

31 Acta del 14 de junio de 1813.

32 Ponemos como ejemplo el Acta del 2 de julio de 1813. Ese día se revisan los expedientes de veintidós personas presentados por los procuradores síndicos. Del total sólo se expulsa a una persona de su cargo. Se conforman tres listas: las dos primeras incluyen a los que tuvieron una conducta patriótica durante la etapa de gobierno intruso; la tercera a los considerados «colaboradores» de los franceses. 
risdicción. En Salamanca existen seis alcaldes de barrio: de la Catedral y agregados, de San Martín y agregados, de Santa María y agregados, de san Julián y agregados, de san Román y agregados y de San Blas y agregados ${ }^{33}$. ¿Qué funciones tenían? Debían hacer rondas para mantener el orden público nocturno, para evitar «abusos y robo de soldados»; esta orden la reciben del jefe político. Ayudan al Ayuntamiento en cuestiones que requieren un conocimiento más cercano de la población como «dar razón de las personas emigradas y que se han ausentado con los franceses» ${ }^{34}$. Los alcaldes de barrio tenían una serie de ayudantes llamados celadores. Los primeros proponían al Ayuntamiento una serie de nombres para los puestos de celador y el Consistorio los elegía ${ }^{35}$.

El escribano del concejo cambia únicamente de denominación, pasando a ser llamado secretario. Su misión consiste en registrar todo lo acordado en el Ayuntamiento. Su presencia es imprescindible para celebrar los consistorios. Según la Constitución, lo primero que ha de hacer el Ayuntamiento una vez tomada posesión es elegir secretario por votación. Hasta que es elegido desempeña este cargo el regidor más moderno. Por ejemplo, al formar el primer Ayuntamiento liberal se hace salir de la sala a Francisco Bellido, secretario, ocupando su puesto el regidor Juan Baquero. Al ser elegido por unanimidad nuevamente Francisco Bellido, vuelve a entrar en la sala y ocupar su $\operatorname{cargo} o^{36}$.

La función del mayordomo tampoco cambia. Está directamente vinculado con la administración de propios de la villa. Es elegido anualmente por el Ayuntamiento y su misión estriba en llevar al día toda la contabilidad derivada de la administración de los propios, debiendo hacerse cargo de todos los ingresos, así como de los pagos que se efectúen y de las compras que deban hacerse. Por ejemplo, en las actas vemos que el mayordomo de propios informa en un oficio al Ayuntamiento sobre la contribución de don Carlos España y de lo que de ella se debe a propios y particulares ${ }^{37}$. Las elecciones a mayordomo son el 11 de septiembre de 1812 entre los candidatos que se presentan al puesto siendo elegidos mediante votación por los regidores ${ }^{38}$.

Junto a estos cargos, debía crearse una Diputación Provincial como órgano intermediario entre el gobierno central y los ayuntamientos ${ }^{39}$. La primera re-

\footnotetext{
33 Encontramos ejemplos de elección de alcaldes de barrio y su distribución por parroquias en las actas del 23 de junio de 1813 y 1 de enero de 1814.

34 Acta del 4 de junio de 1813.

35 En el acta del 7 de enero de 1814 se puede ver una muestra de elección de celadores.

36 Acta del 17 de agosto de 1812.

37 Acta del 3 de septiembre de 1813.

38 Acta del 11 de septiembre de 1812.

39 Artículo 323 de la Constitución: «En cada provincia habrá una Diputación llamada provincial, presidida por el Jefe Superior, para promover la prosperidad de toda ella».
} 
unión de la Diputación Provincial en Salamanca en este periodo tiene lugar el 16 de agosto de $1813^{40}$.

En un primer momento, no quedan claras las competencias respectivas de Ayuntamiento, jefe político y Diputación Provincial. Podemos tomar como ejemplo las discusiones en torno a quién debe desempeñar las funciones de corregidor del ayuntamiento, si corresponde al alcalde o al jefe político. Los regidores toman la decisión de que corresponde al alcalde remitiéndose a la Constitución ${ }^{41}$.

Para resolver estos problemas de delimitación de funciones, las Cortes, en su decreto 269, aprueban la Instrucción para el gobierno económico-político de las provincias el 23 de junio de 1813. Esta orden llega al Ayuntamiento de Salamanca el 9 de agosto de 1813:

«Se vio un oficio del Jefe Político en el que se remite al Ayuntamiento una Instrucción de la Superioridad para el gobierno económico-político de las provincias con las obligaciones del Ayuntamiento, de las Diputaciones y del Jefe Político» ${ }^{42}$.

Para la explicación de la Instrucción de 1813 recurrimos a Javier GARCía FERNÁNDEZ, en el cuarto punto del capítulo ocho de su libro El origen del municipio constitucional ${ }^{43}$. La Instrucción se compone de tres capítulos dedicados a las obligaciones de los Ayuntamientos, las obligaciones y cargas de las Diputaciones Provinciales y a los jefes políticos. Los Ayuntamientos tendrían las competencias en materia de policía de salubridad, censos de población, salubridad contra epidemias, abastos, salubridad en las aguas y en las calles, caminos y obras públicas, beneficencia, montes y plantíos, pósitos, auxilio al alcalde en el orden público, administración de propios y arbitrios, repartimiento y recaudación de contribuciones, establecimiento de educación y por último fomento. El municipio disfruta de competencias siempre en interinidad, pues nada impide que el jefe político llegue a intervenir en mayor o menor grado en esas competencias, con lo que el municipio «dogmática y prácticamente» aparece desposeído de ellas.

Las Diputaciones Provinciales deberían establecer ayuntamientos donde no los hubiere, conservar las obras públicas, auxiliar al jefe político cuando surgiesen enfermedades contagiosas y epidémicas, atribuir las contribuciones a cada municipio, velar por la buena inversión de los fondos de propios y arbitrios de los pueblos, examinar las cuentas de pósitos y velar porque los Ayuntamientos ordenen el establecimiento de escuelas.

\footnotetext{
40 Acta del 25 de agosto de 1813.

41 Acta del 21 de octubre de 1812.

42 Acta del 9 de agosto de 1813.

43 GARCÍA FERNÁNDEZ (1983): 272-278.
} 
El Jefe Político es el presidente del Ayuntamiento de la capital y de la Diputación Provincial. Constituye el único conducto de comunicación entre el Ayuntamiento y la Diputación, tiene el derecho a circular las leyes y decretos, a suspender a los miembros de la Diputación y aprobar las cuentas de propios y arbitrios.

GARCÍA FERNÁNDEZ concluye con la idea de que es una ley absolutamente centralizadora. En esta conclusión coincide con Sánchez-Arcilla para quien «la Instrucción da claramente poderes a las Diputaciones sobre los Ayuntamientos, a quien rigen, controlan y deben ayudar económicamente donde éstos no sean capaces de abarcar» ${ }^{44}$.

En el caso de Salamanca, con fecha 25 de agosto (dieciséis días después de su recepción),

«se vio la Instrucción para el gobierno económico de la provincia, su fecha 26 de junio del corriente ${ }^{45}$, y se acordó su cumplimiento en todas sus partes» ${ }^{46}$,

y en este mismo día la Diputación comienza a exigir su cumplimiento:

«que se arreglen en el destino de los fondos de propios y arbitrios según la Instrucción» ${ }^{47}$.

Otra de las pocas referencias explícitas a la Instrucción se produce el 4 de febrero de 1813:

«El jefe político manda según la Instrucción para el gobierno económico-político de las provincias que se pase noticia del estado en que se hallan los diferentes objetos puestos al cuidado de los Ayuntamientos»

a lo que se contesta, como es costumbre, que se remitirá a la mayor breve$\mathrm{dad}^{48}$.

\section{Competencias}

A continuación, vamos a analizar cómo se ejercen (si lo hacen) en el Ayuntamiento salmantino algunas de las principales competencias que la Constitución ${ }^{49}$ y la Instrucción otorgan a los Ayuntamientos.

\footnotetext{
44 SÁNCHEZ ARCILla (1983): 660.

45 El acta nos da como fecha de la Instrucción la del 26 de junio y no la del 23 como indican ARTOLA y GARCÍA FERNÁNDEZ.

46 Acta del 25 de agosto de 1813.

47 Acta del 25 de agosto de 1813.

48 Acta del 4 de febrero de 1813.

49 Según lo dispuesto en el artículo 319.
} 


\subsection{Salubridad}

Existe una comisión de Policía encargada de los temas de salud pública. En un principio, la forman tres regidores ${ }^{50}$ y posteriormente cuatro ${ }^{51}$. Entre sus funciones está, por ejemplo, encargarse de la limpieza de las calles: el 8 de septiembre de 1812, con motivo de las fiestas, se ordena la limpieza de calles y entrada a comedias; el 25 de junio de 1813 el Ayuntamiento hace presente la necesidad de limpiar las calles para evitar una peste y se pide a los pueblos que concurran con carros para limpiar, primero ganaderos y luego labradores.

El peligro de peste era latente: el 29 de octubre de 1812 se manda la limpieza de la cárcel para evitar la peste.

Otras actuaciones del Ayuntamiento respecto a temas sanitarios que encontramos en las actas son: el 8 de octubre de 1813, se ordena vacunar a los niños de la viruela; el 15 de octubre del mismo año se matan las reses enfermas del matadero y se lleva a la cárcel al abastecedor y pesador Juan Martín; un último ejemplo podría ser el del 24 de diciembre, cuando el Ayuntamiento ordena abrir una calleja debido a que allí se dejaban inmundicias perjudiciales para la salud pública.

Para terminar con el tema de la sanidad, tenemos que hacer referencia a la formación de una Junta de Sanidad el 25 de agosto de 1813 «conforme a la Constitución» compuesta por el alcalde primero, un procurador síndico, Joaquín Maestre, Mauricio Baradart, Francisco DE las Heras y el párroco más antiguo de la ciudad. Pero su formación no implica su inmediata actuación: el 17 de septiembre del mismo año, el jefe político tiene que mandar funcionar a la Junta de Sanidad. A partir de ese día ya no hay más referencias en las actas a dicha junta, por lo que no podemos saber si cumplía o no con su misión.

\subsection{Orden público}

De este apartado se encarga también la comisión de Policía junto al Obrero Mayor. ¿Qué clase de problemas suceden en Salamanca? Vamos a recoger una serie de ellos encontrados en las actas. Los escándalos en las comedias, con las peticiones de los vecinos para que el Ayuntamiento controle esos desmanes ${ }^{52}$; se teme la actuación de las tropas dentro de la ciudad y se intenta controlarlas: por ejemplo, el 19 de julio de 1813 el alcalde primero vizconde de Revilla decide «dar quartel a las tropas para evitar desmanes con los vecinos y salidas nocturnas»; el 3 de enero de 1814, el jefe político manda que se formen partidas de escopeteros voluntarios destinados a la seguridad pública.

\footnotetext{
$50 \quad$ Acta del 17 de agosto de 1812.

51 Acta del 3 de junio de 1813.

52 Acta del 28 de octubre de 1812.
} 
Además de la comisión de Policía y el Obrero Mayor, había un alguacil encargado de velar por el orden público. Existen algunos problemas con esta figura. Ya los detectamos ante la queja del jefe político por su pasividad ${ }^{53}$, lo que podría deberse a la falta de liquidez del Ayuntamiento ${ }^{54}$. Los problemas con el alguacil vuelven a aparecer; «actúa por su cuenta y no da cuenta de lo que hace a los comisarios de Policía» ${ }^{55}$. Otro aspecto importante es la formación de una Junta de Seguridad Pública compuesta por un miembro del Ayuntamiento y cuatro vecinos $^{56}$. Esta Junta no tiene claras sus funciones. Con fecha de primero de octubre pide «cuáles son sus obligaciones» y recibe la contestación de que se ocupen de la seguridad exterior, ya que para la seguridad interior (entrar en casas u otros lugares privados) necesitaban del mandato de la jurisdicción.

Un último aspecto dentro del orden público es la obligación de establecer rondas de vigilancia. El Ayuntamiento suele desentenderse de este tema y el jefe político tiene que recordar en ocasiones la obligación de asistir a las rondas ${ }^{57}$.

\subsection{Repartimiento y contribución}

Este tema competía a los comisarios de la comisión de Abastos y Camarilla, hasta la aparición de la Junta de Contribución Directa.

El principal problema que tiene el Ayuntamiento de Salamanca al respecto es la «contribución extraordinaria directa de guerra». El 7 de julio de 1813 se ordena al Ayuntamiento que comience a activarla. Al parecer, esta contribución era muy gravosa para Salamanca y su provincia pero hasta el 31 de agosto no se pone en marcha. El 3 de septiembre queda elegida la Junta de Repartimiento, con tres representantes del Ayuntamiento, uno del Cabildo, uno de la Clerecía, uno de la Universidad, dos por los hacendados, dos por el comercio, tres por los artesanos. Un total de trece. Aún así no la llevan a cabo. El 26 de noviembre, el jefe político manda cinco ejemplares de los decretos superiores para el repartimiento de la contribución directa extraordinaria de guerra. El Ayuntamiento, en votación ${ }^{58}$, acuerda que la provincia está discriminada porque paga más que otras. Al parecer, la primera Junta de Repartimiento fue anulada porque ese mismo día 26 se vuelve a formar una nueva Junta de Repartimiento compuesta por: como presidente, el alcalde primero, vizconde de Revilla, dos representantes de los hacendados, dos por el comercio, uno por los ganaderos, dos por los

\footnotetext{
53 Acta del 31 de octubre de 1812.

54 En el acta del 1 de septiembre de 1812 encontramos la primera queja del alguacil, referente al dinero que se le adeuda, queja que se irá repitiendo sucesivamente en actas posteriores.

55 Acta del 17 de septiembre de 1813.

56 Acta del 24 de septiembre de 1813.

57 Acta del 4 de febrero de 1814.

58 Acta del 26 de noviembre de 1813.
} 
fabricantes, uno por los labradores, dos por los menestrales, el párroco más antiguo y los dos señores procuradores síndicos alternándose entre si ${ }^{59}$. Su número total sigue siendo de trece componentes. En el acta de 29 de noviembre podemos apreciar que la Junta de Repartimiento tiene potestad sobre el Ayuntamiento en la cuestión de la contribución directa.

El 23 de diciembre de 1813 se manda una representación a la Diputación Provincial alegando que la contribución es excesiva para la ciudad y su provincia. Las quejas aún colean el 31 de diciembre, donde observamos el mismo tipo de protestas. El 3 de enero de 1814, seis meses después del primer mandato desde el gobierno central, la Diputación se ve obligada a exigir al Ayuntamiento que se active la contribución. Ese mismo día el intendente da un plazo de diez días para el pago del primer tercio de la contribución; el 12 de enero, a falta de un día para cumplir el plazo marcado, el jefe político y el intendente vuelven a dar aviso de que han de realizar el pago de la contribución directa extraordinaria de guerra, a lo que el Ayuntamiento responde «que no se cesa de trabajar al respecto» ${ }^{60}$. La propia Junta no tiene muy claro cómo ha de llevarse a cabo el reparto del pago de la contribución. Dudan sobre si deben contribuir los bienes nacionales y las comunidades religiosas; tras consultar con el Ayuntamiento, la respuesta es afirmativa ${ }^{61}$. Las nuevas dudas son: quiénes se deben tener por jornaleros, ¡dicen «no tener ejemplar alguno de la Constitución, ni de la Instrucción, ni de las demás órdenes sobre contribución»!, piden que se formalice la oficina permanente de la Junta de Contribución; esto ocurre a 25 de enero. Este mismo día el jefe político pide «el pago inmediato del tercio de la contribución»; el Ayuntamiento vuelve a excusarse diciendo «se trabaja mucho y hay muchos obstácu$l o s »^{62}$. El tema del pago del tercio de la contribución se va demorando, como encontramos reflejado en las diferentes actas ${ }^{63}$; día clave en el devenir del pago de la contribución es el 29 de marzo, en el cual se celebra un Ayuntamiento extraordinario por la tarde en el que se decide mandar al vizconde de Revilla y Francisco CRESPO RASCÓN «a quejarse de lo excesivo de la contribución directa» a Madrid ${ }^{64}$. El tema sigue ocupando líneas en las actas municipales. Podemos dar este tema por concluido el 4 de julio, con la llegada de una carta en la que el vizconde de Revilla y Francisco CRESPO RASCón informan al Ayuntamiento del cese de la contribución directa y la vuelta de la ordinaria, por lo que el consistorio salmantino no ha realizado el pago de dicha contribución extraordinaria pasado un año desde su solicitud. Suponemos que la falta de interés que

\footnotetext{
59 De una junta a otra observamos notables diferencias respecto a su composición: desaparecen los representantes del Cabildo, la Clerecía y la Universidad y se incorporan ganaderos, labradores, fabricantes y menestrales.

60 Acta del 12 de enero de 1814.

61 Acta del 17 de enero de 1814.

62 Acta del 25 de enero de 1814.

63 Actas del 28 de enero, 11 y 28 de febrero, 4, 14 y 28 de marzo de 1814.

64 Acta del 29 de marzo de 1814, por la tarde.
} 
denota el tema a partir del nueve de mayo se debe a la entrada del Rey Fernando VII en Madrid el cuatro de mayo; los representantes salmantinos, el vizconde de Revilla y Francisco Crespo Rascón, pertenecen al círculo influyente de la sociedad de Salamanca y suponemos que próximos al monarca (el vizconde es regidor perpetuo de Salamanca desde 1808, y Francisco CRESPO RASCÓN fue nombrado por el propio rey como «Ministro de la Real Chancillería de Valladolid» en fecha de 22 de agosto de 1812). También hay que recordar que un mes después, en junio, se produce la disolución de las diputaciones y la desaparición de la figura del jefe político, órganos que apremiaban el pago de la contribución.

\subsection{Educación}

El principal problema es la falta acuciante de fondos para pagar sus sueldos a los maestros de las escuelas de primeras letras; los retrasos son frecuentes; en el consistorio de 21 de agosto encontramos una queja de estos maestros y se les informa que el pago se hará de los fondos de Abastos así como se manda hacer un informe por los comisarios de Escuelas de lo que habrán de cobrar en lo sucesivo dichos maestros y de dónde se les debe pagar ${ }^{65}$. Posteriormente, el Ayuntamiento se excusa ante los maestros diciendo que esos pagos son competencia de la Diputación Provincial ${ }^{66}$.

\subsection{Hospitales}

Se mantienen gracias a lo que el Ayuntamiento pide a los ciudadanos (mantas, camas, ropas, etc.) Ante la situación de guerra, se crea una comisión de Hospital Militar en el primer Ayuntamiento. Más tarde, encontramos una Junta de Hospital Civil con Francisco DE LAS HERAS como presidente junto a seis eclesiásticos y cinco seculares, entre ellos el marqués de Cerralbo, la condesa de Francos y Pedro TiBurcio GutiéRrez. Como ejemplo de los problemas, nos remitimos al acta del 28 de enero de 1814 en el que la Junta de Hospital manda un oficio al Ayuntamiento porque «no tienen ni fondos ni arvitrios con que sostenerse». El consistorio acuerda dar unos pocos fondos pero trasladan la responsabilidad sobre el tema al Intendente. También ordenan que los días festivos se pida dinero para los pobres del hospital.

\subsection{Obras públicas}

Es un ámbito reservado para el Obrero Mayor y el maestro arquitecto. Los asuntos conciernen sobre todo a problemas con edificios ruinosos y peticiones

65 Acta del 21 de agosto de 1812.

66 Acta del 24 de septiembre de 1813. 
de los vecinos para realizar determinadas obras, además del requerimiento de los militares para que se hagan reformas con vistas al alojamiento de tropas y a la defensa de la ciudad. Tenemos ejemplos en las actas: sobre ruinas, el 16 de junio de 1813, el maestro arquitecto informa al Ayuntamiento de que hay que derribar unos edificios ruinosos y así se decide que se derriben, dando parte el secretario de la decisión a sus dueños en el plazo de tres días; sobre peticiones de vecinos, el 20 de septiembre Anselmo Prieto Hermosino pide una licencia para construir un balcón en su casa de la Plaza Mayor, permiso que se le concede el 25 de octubre; en cuanto a las tropas, el 1 de septiembre de 1812 se realizan obras en Santa Marta por petición de Wellington para defender la zona.

\subsection{Beneficencia}

La cuestión que más aparece en las actas es la relacionada con los niños expósitos. Los problemas económicos del Ayuntamiento hacían que la Casa de Niños Expósitos se encontrara en una ruina absoluta. Muchos niños morían. Además, el Ayuntamiento dice que solucionar los problemas de la Casa no es su responsabilidad y sí de la Diputación Provincial, a lo que ésta contesta de forma similar, achacando la responsabilidad al Municipio. Algunos problemas concretos: el administrador de la Casa, don José María VALLADARES expone una falta de fondos y rentas y una deuda de cuarenta mil reales y pide dinero al Ayuntamiento «porque la urgencia es grande» ${ }^{67}$. El Ayuntamiento ignora dicha urgencia y se remite a la Diputación Provincial. En otra ocasión, la Diputación ordena al Ayuntamiento que pague a la Casa de Niños Expósitos los 27500 reales que se le deben. El Ayuntamiento se niega a hacerlo alegando que no hay dinero ${ }^{68}$.

El Consistorio colabora en el mantenimiento del convento de dominicos pasando repetidamente las raciones alimenticias mientras tiene dinero; cuando no le es posible remiten el encargo al intendente a quien el Ayuntamiento dice corresponder esta función ${ }^{69}$.

Una vez más, no está clara la delimitación de competencias entre el Ayuntamiento y los organismos superiores, o quizá se limitan a pasarse los problemas y no resolverlos.

\section{Cumplimiento de las órdenes superiores}

Ya hemos visto anteriormente cómo el Ayuntamiento se niega o retrasa la puesta en práctica de ciertas órdenes superiores (contribución directa, la Instruc-

\footnotetext{
67 Acta del 25 de junio de 1813.

68 Acta del 15 de octubre de 1813.

69 Acta del 21 de agosto de 1812.
} 
ción, la tardanza en el funcionamiento de las Juntas, la ausencia de las rondas, etc.). Pero existen otros muchos ejemplos de mandatos superiores que no son cumplidos. Una buena parte de ellos están relacionados con el abastecimiento de las tropas. Como muestra, el 28 de mayo de 1813, el intendente manda que no falten raciones a las tropas pero el Ayuntamiento expone su imposibilidad de abastecerlas por falta de fondos, por no tener arbitrios ni la «competente orden para repartir contribución al vecindario». Una semana más tarde vuelven a informar al intendente de que no pueden abastecer a las tropas. Sin embargo, el 27 de agosto el jefe político reprende al Ayuntamiento diciendo que «no debió dar facultad para recaudar el donativo para el Regimiento de Cazadores de Castilla». ¿Por qué el Ayuntamiento en este caso no se declaró incompetente? Lo ignoramos.

Otro aspecto importante es el relacionado con la asistencia al Ayuntamiento de los alcaldes y regidores. El 30 de septiembre de 1813, el jefe político preside el Ayuntamiento, pero sólo se presentan al mismo cinco regidores y ningún alcalde. El enfado del jefe político se manifiesta el día 1 de octubre, exponiendo en el Ayuntamiento «la falta de concurrencia de los señores en las actas consistoriales». Entonces se acordó que «al pie de la citación exponga cada uno de dichos señores el motivo que tenga para no concurrir al Ayuntamiento a fin de tomar la Providencia correspondiente». En ningún momento se cumple esto pues no encontramos ningún día en el que se den motivos de las ausencias. Pasada una semana, el jefe político vuelve a presidir la reunión municipal y manda «no faltar lunes y viernes con preferencia a toda Junta». Esta orden es ignorada por completo ya que según se aprecia en las actas, cada miembro asiste cuando le parece, sin ninguna obligación al respecto. Buscando un ejemplo claro, podemos decir que el alcalde primero para el año 1814, Martín José LATARAIN asiste el 1 de enero a tomar posesión, pero no vuelve al Ayuntamiento hasta la reunión extraordinaria del día 12 de marzo por la tarde.

Otra orden que pasan por el alto es la de efectuar el alistamiento, sorteo de quintas y recogida de vagos para el ejército. Continuamente, la superioridad pide al Ayuntamiento que acelere las diligencias para tal fin pero no se hace nada. La creación de una Junta de Alistamiento es meramente testimonial. El jefe político ordena que el sorteo se celebre el 29 de octubre de 1813, pero no se realiza. Dos días después, el jefe político vuelve a ordenar la celebración del sorteo, pero a partir de ahí las actas no dan ninguna noticia más sobre el tema.

Un último ejemplo que podemos poner es el de la negación por parte del Ayuntamiento a hacerse cargo de los presos de la cárcel: «El jefe político hace cargo por un decreto al Ayuntamiento de los presos de la cárcel», a lo que se contesta «el Ayuntamiento no tiene facultades para sostener a los presos» ${ }^{70}$.

Existen otras muchas ocasiones en las que el Consistorio no cumple las órdenes superiores pero sería demasiado extenso referirse aquí a todas ellas. Esto

70 Acta del 5 de julio de 1813. 
tampoco ocurría de forma generalizada ya que existen también órdenes que sí se acatan. Se suelen aceptar las órdenes que no conllevan un desembolso de dinero por parte del Ayuntamiento (sobre expulsión de franceses ${ }^{71}$, efectuar el censo ${ }^{72}$, proporcionar a la Regencia la lista de rehabilitados en las purificaciones ${ }^{73}$, que las Juntas de Policía y Vigilancia sean una sola bajo el nombre de Policía ${ }^{74}$, etc.).

\section{Desacuerdos y votaciones}

Cuando no hay consenso sobre un tema se recurre al sistema de votación; este sistema sigue un mismo mecanismo de ejecución. Cada miembro del Ayuntamiento puede dar su opinión sobre el tema o adherirse a una posición ya manifestada por algún componente del consistorio previamente. Una vez oídas todas las posturas se efectúa la regulación de voto, consistente en que cada miembro puede variar su opinión inicial tras oir todos los testimonios. Se establece el recuento de votos y se obra en consecuencia. Mostramos dos ejemplos de sistema de votación: El once de junio de 1813 se discute sobre si se pueden mandar raciones al ejército de reserva. Tras las votaciones se impone la opinión de José Mintegui, quien manifiesta que deben pedir una subvención al Ilustrísimo Cabildo Económico ${ }^{75}$.

En otra ocasión se vota sobre la aceptación o no de la orden de mandar un diputado a Cortes. En esta oportunidad prima la opinión de Diego GonZÁLEZ; «el Ayuntamiento no tiene facultad para revocar la orden» ${ }^{76}$.

Hemos seleccionado estos dos ejemplos porque reflejan la opinión de los dos personajes posiblemente más influyentes dentro del Ayuntamiento de Salamanca, en torno a cuyas posturas giran las decisiones del consistorio salmantino.

No podemos concretar temas generales de discusión, ya que las votaciones se realizan sobre cualquier aspecto de cierta importancia que pudiera llegar al Ayuntamiento, tales como votaciones para elegir un cargo ${ }^{77}$, sobre apoyo económico al ejército (en la que el acuerdo resultante siempre es el de no pagar ${ }^{78}$ ), etc.

\footnotetext{
71 Acta del 2 de julio de 1813: se nombre comisario al regidor Diego GonZÁLEZ para llevar a cabo «la expulsión de franceses y gente de países sujetos a Napoleón» por orden de la Regencia del Reino comunicada por el jefe político al Ayuntamiento el 27 de junio de ese año.

72 Acta del 7 de julio de 1813: se decide que el padrón se realizará «en el término de quince días».

73 Acta del 28 de agosto de 1813.

74 Acta del 13 de octubre de 1813.

75 Acta del 11 de junio de 1813.

76 Acta del 7 de julio de 1813.

77 Algunos ejemplos: elección de tesorero mayor de propios (acta del 11 de septiembre de 1812) o de guarda de árboles (acta del 6 de septiembre de 1813).

78 Acta del 17 de septiembre de 1813. El gobernador militar pide un donativo para las tropas. El Ayuntamiento no lo concede alegando falta de fondos.
} 


\section{Oligarquías municipales}

Hay una serie de personas, sea cual sea el sistema de gobierno, que desempeñan siempre cargos importantes, incluso varios a la vez. Es notable también la presencia de nobles dentro de la administración municipal, tanto absolutista como liberal. Pondremos como ejemplo a una serie de estos personajes.

En primer lugar, los nobles. El vizconde de Revilla es una de las personas más influyentes de la ciudad de Salamanca; ya en el Antiguo Régimen poseía el cargo de regidor perpetuo, bajo el sistema liberal es alcalde primero constitucional del 1 de junio al 31 de diciembre de 1813. A pesar de su salida del Ayuntamiento, seguimos encontrando pruebas de su influencia ya que el Ayuntamiento le elige para ir a Madrid a quejarse de lo excesivo de la contribución directa $^{79}$; a la vuelta del absolutismo, el rey le repone en su cargo de regidor perpetuo ${ }^{80}$. Además, es uno de los más ricos, como se demuestra en la suscripción que el Ayuntamiento hace para las tropas vencedoras en Pamplona, dando cuarenta duros (ochocientos reales) ${ }^{81}$.

El Marqués de Cerralbo ocupa un cargo de regidor en el Ayuntamiento desde agosto a noviembre de 1812 y de mayo a diciembre de 1813. Es un gran potentado, hace muestras ostentosas de su dinero donando veinticinco doblones de oro (10500 reales) a las tropas victoriosas en Pamplona ${ }^{82}$ y pagando en su totalidad la medalla con el busto dedicado al duque de Wellington ${ }^{83}$. Era exempto retirado de Reales Guardias de Corpus; en este sentido, el consejo de Guerra de oficiales generales de Puerto de Santa María pide informe de su conducta política y militar «mientras permaneció entre los enemigos» ${ }^{84}$, mandando el Ayuntamiento informe positivo respecto a su conducta ${ }^{85}$.

El Marqués de Espeja desempeña el cargo de jefe político durante el primer Ayuntamiento liberal. Es nombrado por el ejército para desempeñar dicho cargo ${ }^{86}$.

Por último, observamos la presencia del Marqués de la Escala, como regidor de enero a agosto de 1814.

Hay que señalar que todos los marqueses mencionados reciben en las actas la consideración de excelentísimo señor.

\footnotetext{
79 Ver nota 63 y su contexto.

80 Acta del 12 de agosto de 1814.

81 Acta del 21 de noviembre de 1813.

82 Acta del 21 de noviembre de 1813.

83 Acta del 15 de diciembre de 1813. Ese mismo día se ordenó borrar la medalla dedicada a Godoy.

84 Acta del 11 de noviembre de 1813.

85 Acta del 15 de noviembre de 1813.

86 Acta del 16 de octubre de 1812.
} 
Fuera del ámbito aristocrático también encontramos figuras de relevancia que analizamos a continuación. José DOMINGO MINTEGUI, de cierta importancia y prestigio en la ciudad, catedrático universitario; ya era diputado del Común en los años 1807-1808 y rápidamente entra a formar parte del Ayuntamiento. En cuanto D. Carlos de España recupera Salamanca nos encontramos a José Mintegui en el consistorio ${ }^{87}$; desempeña el cargo de regidor desde agosto hasta noviembre de 1812, y de mayo hasta el 6 de septiembre de $1813^{88}$. No cumple la totalidad de su elección como regidor ya que en esta fecha se marcha del Ayuntamiento al ser elegido diputado de las Cortes, cargo del que toma posesión el 24 de octubre. Ese mismo año de 1813 es nombrado por las Cortes miembro de la Junta Censoria de Salamanca. Es nombrado jefe político interino por la Regencia del Reino, pero esta decisión es revocada por el Rey ${ }^{89}$. Con la reposición del absolutismo vuelve a su antiguo cargo de diputado del Común.

Otro personaje de fecunda actividad es Juan Francisco de las Heras. La primera referencia que encontramos en nuestro estudio acerca de esta persona nos remite a la ocupación francesa ${ }^{90}$. A pesar de desempeñar cargos bajo la dominación gala le vemos formando parte del Ayuntamiento tras la liberación de la ciudad por don Carlos de España ${ }^{91}$, siendo posteriormente elegido para ocupar cargo como regidor del 1 de enero de1814 hasta la descomposición del Ayuntamiento liberal con la vuelta del absolutismo. Además es miembro de la Junta de Sanidad, de la Junta de Repartimiento y presidente de la Junta de Hospital Civil ${ }^{92}$.

Ahora mencionaremos otras personas que desempeñan cargos dentro del Ayuntamiento pero con menor influencia. Los individuos que señalamos a continuación muestran la peculiaridad de formar parte tanto del consistorio de época francesa como del impuesto por D. Carlos de España: Sebero MANSILLA, Manuel Arteaga, José Aguirre, Miguel Pérez e Isidro AguAdo. Sólo falta José CONDADO, quien ocupaba el puesto de corregidor, cargo que volverá a desempeñar en la segunda etapa de ocupación francesa.

\section{CONCLUSIÓN}

La conclusión más relevante que podemos sacar de este estudio del Ayuntamiento salmantino de 1812 a 1814 es que no se consigue aplicar en él la idea municipal de las Cortes de Cádiz.

\footnotetext{
87 Acta del 24 de junio de 1812. Hemos de suponer que ya formaba parte de él, ya que D. Carlos de España repone el Ayuntamiento anterior a la ocupación francesa.

88 Acta del 6 de septiembre de 1813.

89 Acta del 14 de junio de 1813.

90 Acta del 13 de marzo de 1812.

91 Acta del 24 de junio de 1812.

92 Constituidas las dos primeras el 25 de agosto y 3 de septiembre de 1813, y la última el 21 de enero de 1814.
} 
Como hemos visto, los organismos superiores creados por la Constitución y reafirmados por la Instrucción (Jefe Político y Diputación Provincial), no pueden imponer sus órdenes sobre el Ayuntamiento, lo que es en parte debido a la situación de guerra. Si alguna norma consigue imponerse desde la superioridad es después de un largo período de tiempo de insistencia, de debate en el Ayuntamiento y de propia interpretación por parte de éste. Incluso la desaparición de los organismos del Antiguo Régimen es costosa; una vez instaurado el municipio constitucional en Salamanca encontramos referencias en las actas a los cargos de corregidor y alcalde mayor ${ }^{93}$.

Otro hecho a favor de nuestro argumento es el inmovilismo que se aprecia acerca de la ocupación de cargos por ciertas personas. Ciertamente, desaparecen los regidores perpetuos, pero el poder e influencia de las personas que habían ostentado dicho cargo en el municipio es mucho mayor del que puedan tener el Jefe Político o la Diputación e incluso alguno de ellos logra ocupar el cargo de alcalde constitucional, como es el caso del vizconde de Revilla. Por tanto, afirmamos que las oligarquías que dominan los designios del Ayuntamiento de Salamanca no cambian respecto al Antiguo Régimen.

\section{FUENTES}

Archivo Histórico Municipal de Salamanca: Actas municipales: de 13 de marzo de 1812 a 12 de agosto de 1814.

Constitución Española de 1812

\section{BIBLIOGRAFÍA}

Artola Gallego, Miguel, La España de Fernando VII, Historia de España de Menéndez Pidal, v.XXXII, Madrid, Espasa-Calpe, 1978.

Comellas, José Luis, «Las Cortes de Cádiz y la Constitución de 1812», Revista de Estudios Políticos, N. ${ }^{126}$, Nov-Dic. 1962, Págs., 69-109.

GARCÍA FERNÁNDEZ, Javier, El origen del municipio constitucional, Madrid, Instituto de la Administración Local, 1983.

SÁNCHEZ-ARCILla BERNAL, José, «Del municipio del Antiguo Régimen al municipio Constitucional. Un caso concreto: Guadalajara», Actas del IV Symposium de Historia de la Administración, Madrid, Instituto Nacional de Administración Pública, 1983.

VILlar y Macías, Manuel, Desde la Guerra de Independencia a nuestros días. Historia de Salamanca, v. IX, Salamanca, Grafiesa, 1975.

93 Actas del 1 de junio de 1813 y del 17 de mayo de 1814 . 